\title{
REVIEW
}

\section{Chromosomal disorders and male infertility}

\author{
Gary L Harton ${ }^{1}$ and Helen G Tempest ${ }^{2}$
}

Infertility in humans is surprisingly common occurring in approximately $15 \%$ of the population wishing to start a family. Despite this, the molecular and genetic factors underlying the cause of infertility remain largely undiscovered. Nevertheless, more and more genetic factors associated with infertility are being identified. This review will focus on our current understanding of the chromosomal basis of male infertility specifically: chromosomal aneuploidy, structural and numerical karyotype abnormalities and Y chromosomal microdeletions. Chromosomal aneuploidy is the leading cause of pregnancy loss and developmental disabilities in humans. Aneuploidy is predominantly maternal in origin, but concerns have been raised regarding the safety of intracytoplasmic sperm injection as infertile men have significantly higher levels of sperm aneuploidy compared to their fertile counterparts. Males with numerical or structural karyotype abnormalities are also at an increased risk of producing aneuploid sperm. Our current understanding of how sperm aneuploidy translates to embryo aneuploidy will be reviewed, as well as the application of preimplantation genetic diagnosis (PGD) in such cases. Clinical recommendations where possible will be made, as well as discussion of the use of emerging array technology in PGD and its potential applications in male infertility.

Asian Journal of Andrology (2012) 14, 32-39; doi:10.1038/aja.2011.66; published online 28 November 2011

Keywords: chromosomal aneuploidy; chromosomal translocation; intracytoplasmic sperm injection; in vitro fertilization; male infertility; non-disjunction; preimplantation genetic diagnosis; Y-chromosome microdeletion

\section{INFERTILITY}

Infertility is a relatively common problem that affects couples worldwide. It is estimated that approximately 1 in 6 couples will experience difficulties in reproducing, ${ }^{1,2}$ defined as a failure to conceive after two years of unprotected sexual intercourse. It is clear that fertility problems affect both males and females; ${ }^{3}$ in some situations, the cause of the infertility is clearly defined, such as a mechanical obstruction for example. However, for the most part, a large proportion of infertility remains idiopathic, although more and more genetic factors have been identified and demonstrated to affect fertility. This review will focus on factors associated with primary spermatogenic factors: specifically chromosomal factors associated with male infertility will be addressed as well as the risk of spontaneous abortions and aneuploid offspring. Chromosomal aberrations, either numerical or structural in nature, can have profound effects on fertility. The frequency of chromosomal aberrations in the general population is approximately $0.6 \%{ }^{4}$ However, karyotype abnormalities are reported in $2 \%-14 \%$ of males presenting with infertility. ${ }^{5}$ Increases in chromosomal aberrations have been clearly demonstrated to increase proportionally with increasing severity of the infertility. This review will also discuss recommendations for genetic counseling, application of preimplantation genetic diagnosis (PGD) and perspectives on future applications of emerging technologies and their potential use in male infertility.

\section{CHROMOSOMAL ANEUPLOIDY}

Chromosomal aneuploidy refers to an alteration in chromosomal number from the normal diploid chromosomal complement in somatic cells or haploid complement in gametes. Chromosomal aneuploidy is the leading cause of pregnancy loss and developmental disabilities in humans. ${ }^{6}$ Aneuploidy can be either numerical or partial in nature involving either gain or loss of an entire chromosomal; or structural involving a gain or loss of a segment of a chromosome.

\section{Numerical chromosomal aneuploidy}

Chromosomal aneuploidy is, for the most part, catastrophic for development and has been reported for all chromosomes in spontaneous abortions. In humans, aneuploidy is surprisingly common occurring in around $4 \%$ of clinically recognized pregnancies. ${ }^{7}$ However, it is estimated that up to $60 \%$ of conceptions are aneuploid but are spontaneously aborted, often even before a pregnancy is clinically recognized. ${ }^{7}$ It is also evident that loss (monosomy) of a chromosome is much more detrimental than gain (trisomy) of a chromosome. Monosomy $\mathrm{X}$ is the only non-mosaic monosomic condition that is compatible with life, and is largely attributed to X chromosome inactivation (Lyonization). ${ }^{8}$ In contrast, there are a handful of chromosomes $(13,18,21, \mathrm{X}$ and $\mathrm{Y})$ that in a trisomic state can survive to term. Nevertheless, it should be noted that while aneuploidy for these chromosomes is compatible with live birth, the vast majority will be spontaneously aborted early on during development. 
The genesis of chromosomal aneuploidy has been reviewed in detail elsewhere, ${ }^{6,7,9,10}$ but in brief can occur as the result of a meiotic non-disjunction event in gametes, precocious separation of chromatids, ${ }^{11-13}$ or as a post-zygotic mitotic non-disjunction event in the embryo. It has long been established that advancing maternal age is the highest risk factor for aneuploid conceptions. ${ }^{9}$ The advent of in vitro fertilization (IVF) in conjunction with PGD has enabled the chromosomal complement of cultured human embryos to be determined. PGD will be discussed in more detail later in subsequent sections, but in brief, the chromosomal complement of an embryo can be determined by removing a single blastomere from 3-day-old (eightcell-stage) embryo or by removing a small bit of trophectoderm from an embryo at the blastocyst stage. Once biopsied, the chromosomal complement of the embryo can be determined by utilizing fluorescence in situ hybridization (FISH) on the isolated blastomere using specific chromosome probes of interest, or, more recently, using array-based methods to examine all 24 chromosomes. PGD has been performed by clinics worldwide for the past two decades. ${ }^{14,15}$ The use of PGD clinically has provided valuable information regarding the incidence of aneuploidy in early development. This data suggest that a high proportion of cleavage-stage embryos produced in vitro are chromosomally abnormal, greater than $50 \%$ even in reproductively 'young' women, increasing to up to $80 \%$ in women over 42 years of age. $^{16-19}$ Although extended culture will eliminate some of these abnormal embryos, a relatively high proportion continue on through embryo development, and even at the blastocyst stage, more than half of all embryos are abnormal (mean maternal age: 38 years). ${ }^{20}$ The impact of aneuploidy in early embryos is illustrated by the high prevalence of chromosomal abnormalities detected in spontaneous abortions, exceeding $70 \%$ in some studies. ${ }^{21-26}$ Removal of aneuploid embryos during assisted reproductive techniques (PGD of aneuploidy or preimplantation genetic screening) has been proposed as a way to improve success rates. ${ }^{27}$

To date, very little is known about the role that sperm aneuploidy plays in infertility or assisted reproduction. Current thought is that most aneuploidy in early embryos is predominantly derived from female non-disjunction $(\sim 95 \%)$ or is mitotic in origin, with the exception of aneuploidy of the sex chromosomes which is paternal in origin in $50 \%-100 \%$ of cases. ${ }^{7}$ However, very little clinical information can be found on the male contribution to aneuploidy in cleavage-stage embryos. To date, sperm aneuploidy levels have been assessed using FISH in over 50 studies (reviewed by Refs. 5, 28 and 29). These studies have predominantly assessed aneuploidy levels for different chromosomes in fertile and infertile men. It is evident from these studies that all men have a proportion of aneuploid sperm in their ejaculate. Levels of aneuploid sperm in fertile men have been reported to be around $3 \%-5 \%$; virtually all studies investigating sperm aneuploidy levels in infertile men have demonstrated a significant increase in aneuploidy levels compared to their fertile counterparts. ${ }^{5,28,29}$ The vast majority of studies report around a threefold increase in sperm aneuploidy levels in infertile men. Increases in sperm aneuploidy have been reported for all infertility phenotypes including oligozoospermia (low concentration), asthenozoospermia (poor motility) and teratozoospermia (poor morphology). It is clear that increased frequencies are strongly correlated with increasing severity of infertility with the highest levels reported in men with severe oligoasthenoteratozoospermia and sperm retrieved from testicular sperm extraction in cases of non-obstructive azoospermia. ${ }^{5,28,29}$ However, despite the increase in aneuploidy frequencies, physicians rarely order aneuploidy screening for a male indication ${ }^{30}$ except, perhaps, for a rare case requested based on very low sperm counts and the need for surgical or non-surgical collection of sperm from the testes. This is most likely due to the fact that the issue of increased sperm aneuploidy in certain patient cohorts is a complex one and raises many questions, which remain to be answered. In particular, does increased sperm aneuploidy actually translate to an increased risk of producing aneuploid conceptions and how should patients with increased levels of sperm aneuploidy be counseled? ? $^{3,31-33}$ The following sections summarize our current understanding of the paternal contribution of aneuploidy.

\section{HOW DOES SPERM ANEUPLOIDY TRANSLATE TO RISK OF ANEUPLOID OFFSPRING?}

Unlike in PGD where it is possible to analyze the chromosomal complement of a single cell derived from an embryo, at present we have no way to assess the chromosomal complement of individual sperm to be used in IVF or intracytoplasmic sperm injection (ICSI), as the sperm is unfortunately destroyed in the process. Thus, even though assessment of aneuploidy in sperm is relatively straightforward to carry out, it is not yet clear how aneuploidy assessments can or should be used to counsel patients. ${ }^{31-33}$ Given that we are unable to test individual sperm to be used in IVF or ICSI, this question is obviously difficult to address and is confounded by the large maternal contribution to aneuploidy. Nevertheless, attempts are being made to address this using several different approaches. To date, a handful of studies have retrospectively assessed the levels of sperm aneuploidy in men who have previously fathered paternally derived aneuploid offspring. ${ }^{34-38}$ These studies suggest that, in almost all cases, the levels of aneuploidy in the sperm of these individuals are significantly higher than those reported in normal fertile men with no history of aneuploid offspring. One such study reported some of the highest sperm aneuploidy levels in one individual who subsequently fathered four consecutive aneuploid offspring (two of which were confirmed to be paternal in origin). ${ }^{39}$ It is also interesting to note that there is an apparent interchromosomal effect (ICE), as increases are frequently reported not just for the chromosomes involved but also for other investigated chromosomes. ${ }^{34}$ While this does not provide a direct link between sperm aneuploidy and the likelihood of aneuploid offspring, it has highlighted the fact that a proportion of individuals do have a generalized tendency for non-disjunction in their sperm and that this may result in aneuploid conceptions. Other studies have attempted to correlate sperm aneuploidy, male infertility and reproductive outcomes. It is clear from the published data that sperm aneuploidy is correlated with the severity of the male infertility (reviewed by Refs. 5 and 29). However, emerging data from several studies have demonstrated that higher levels of sperm aneuploidy are also associated with recurrent ICSI failure; ${ }^{40,41}$ increased chromosomal abnormalities in embryos; ${ }^{42}$ and lower pregnancy rates and live births. ${ }^{43}$ These studies taken collectively do not provide direct evidence of the paternal contribution to aneuploidy, but certainly suggest that sperm aneuploidy may play a more significant role in aneuploid conceptions than is currently recognized in the field of reproductive medicine. In subsequent sections, we review the use of array based approaches which have the potential to determine the paternal contribution to aneuploidy in embryos.

\section{Mechanism and risk of producing aneuploid sperm in males presenting with karyotype abnormalities}

Individuals with karyotypic abnormalities, either numerical or structural in nature, have an obvious predisposition to chromosomally 
abnormal conceptions. As a result, they often present with infertility due to failure of achieving a successful pregnancy, often due to repeated spontaneous abortions. The major types of karyotype abnormalities that frequently can result in reduced fertility, namely, chromosomal translocations or inversions, aneuploidy and Y chromosomal microdeletions, will be discussed in further detail.

\section{CHROMOSOMAL TRANSLOCATIONS AND MALE INFERTILITY}

Balanced chromosomal translocations involve breaks in two chromosomes and abnormal repair of the chromosomal fragments resulting in the transposition of genetic material from one chromosome to another without the loss of any genetic material. In the vast majority of cases, carriers of balanced translocations are themselves phenotypically normal, unless one of the translocation breakpoints interrupts an important gene or via position effects. Should a gene be translocated into a region in which expression is either up- or downregulated, it can result in an increased risk of cancer, for example, the translocation could inactivate a tumor suppressor gene or activate an oncogene. ${ }^{44}$ Nevertheless, carriers of balanced chromosomal translocations, while normal phenotypically, may experience reduced fertility, spontaneous abortions or birth defects. ${ }^{45}$ Normal meiotic segregation of these translocations in the gametes can lead to duplication or deletion of the chromosomal regions involved in the translocation. ${ }^{45}$ Reduced fertility in translocation carriers may in part be the result of the requirement during meiosis for chromosomal translocations to form a quadrivalent or trivalent structure (reciprocal and Robertsonian translocations, respectively) to enable homologous chromosomes to pair. The formation of the quadrivalent or trivalent can lead to reduced fertility, firstly, due to the mechanics and time constraints to form such a structure ${ }^{46}$ and secondly, as a result of the disjunction of the structures which is prone to produce genetically unbalanced gametes. ${ }^{45}$ The relative frequency of normal or unbalanced gametes appears to depend largely on the chromosomes involved, the size of the region involved, the presence of heterochromatin, location of the breakpoints (e.g., G-positive or G-negative bands) and likelihood of recombinatorial events to take place within the translocated segments. ${ }^{45}$ The proportion of unbalanced gametes in each balanced translocation carrier varies widely and likely reflects the specific rearrangement involved. It should be noted that levels of unbalanced gametes will be significantly higher than the empiric risk of having a chromosomally unbalanced liveborn due to the fact that many, if not most of the segregant products, will be spontaneously aborted early on in development (depending on the chromosomes and size of the segment involved). ${ }^{45}$

\section{Robertsonian translocations and risk of aneuploid offspring} Robertsonian translocations involve only the acrocentric chromosomes, specifically chromosomes 13, 14, 15, 21 and 22. In this instance, the translocation arises as the result of a centric fusion of two acrocentric chromosomes. In the case of Robertsonian translocations, we have relatively accurate empiric risks of having liveborn affected children given that these translocations involve relatively few chromosomes, all of which have the same breakpoint. ${ }^{45}$ The frequency of unbalanced gametes has been assessed in 20 carriers of balanced Robertsonian translocations. The results from these studies vary widely with reports of 3\%-36\% unbalanced sperm (reviewed by Refs. 33, 47 and 48), significantly higher than the empiric risks of having a paternally derived trisomy 13 or 21 conceptus $(<2 \%)$ in each case.

\section{Reciprocal translocations and risk of aneuploid offspring}

Reciprocal translocations involve exchanges of material between two or more chromosomes, involving at least one non-acrocentric chromosome. In terms of genetic counseling in reciprocal translocation carriers, the situation is much more complicated, given that the vast majority of translocations are unique to individual families. The sperm of 30 balanced reciprocal translocation carriers have been analyzed with much higher levels of genetically unbalanced sperm reported, $29 \%-81 \%$, compared to Robertsonian translocation carriers (reviewed by Refs. 33, 47 and 48). The significant variation in unbalanced gametes reported likely reflects the different chromosomes involved, size of the segments and predisposition of recombination to occur within the translocation region.

\section{PGD for chromosomal translocations}

PGD for chromosomal translocations has been successfully applied when FISH probes specific for the chromosomal translocation are available. However, it should be noted that PGD by FISH is unable to distinguish between embryos with a normal chromosomal complement and one that is a carrier of the balanced translocation. The European Society for Human Reproduction and Embryology (ESHRE) PGD consortium data collection $\mathrm{X}$ detailed the PGD results of 57 centers participating for the calendar year 2007 and reported on a total of 729 cycles to oocyte retrieval for chromosomal translocations. ${ }^{49}$ PGD for reciprocal translocations was more frequently performed than Robertsonian translocations. If we only consider oocytes that were successfully fertilized, biopsied and gave a successful diagnostic result $(n=3652)$, only 26\% (938/3652) were transferable (normal/balanced). ${ }^{49}$ This suggests a very high level of chromosomally unbalanced gametes $(74 \%)$ and is consistent with sperm FISH results and previous ESHRE consortium data showing that individuals with chromosomal translocations produce a very high rate of chromosomally abnormal embryos. In addition, several large American PGD groups have published similar rates of unbalanced embryos and have distinguished between reciprocal and Robertsonian translocations. ${ }^{50,51}$ These studies report $54 \%{ }^{50}$ and $72 \%{ }^{51}$ of embryos to be unbalanced for Robertsonian translocations, with the percentage of unbalanced embryos for reciprocal translocations reported to be $75 \%{ }^{50}$ and $82 \%{ }^{51}$ These data sets clearly provide compelling evidence that structural chromosomal aberrations are able to produce aneuploid gametes, and that these gametes are capable of fertilizing and in turn result in a very high proportion of aneuploid embryos. PGD for structural rearrangements has been very successful in assisting couples to achieve a viable unaffected pregnancy and has certainly reduced the time taken to achieve a pregnancy by reducing the number of spontaneous abortions. ${ }^{45,52}$ However, as FISH is not able to distinguish between normal and balanced embryos, couples should be counseled that while any balanced offspring will be phenotypically normal, they will likely encounter the same fertility problems and risks of liveborn affected children as their parents. It is clear from the published data that only one in four embryos will be likely to be normal or balanced, and it seems that the likelihood of a normal/balanced conception is relative to the baseline of unbalanced gametes.

\section{CHROMOSOMAL INVERSIONS}

As with chromosomal translocations, inversions can cause infertility, spontaneous abortions and birth defects. During meiosis, chromosomes are forced to form specialized structures (inversion loops) to enable homologous chromosomes to pair. The formation of these 
loops can impact fertility due to the mechanics and time constraints associated with the formation of the inversion loop. ${ }^{46}$ Single-sperm PCR has also demonstrated that recombination within these loops is reduced which can lead to a breakdown in meiosis ${ }^{53}$ and hence, may lead to apoptosis of the cell leading to a reduced sperm count. In addition, should recombination take place within the inversion loop, this will produce a proportion of unbalanced gametes. ${ }^{54}$ As with reciprocal chromosomal translocations, the relative frequency of normal or unbalanced gametes will depend on the chromosomes involved, the size of the region involved and likelihood of recombinatorial events to take place within the inverted segments. Investigations into the production of unbalanced gametes in balanced inversion carriers have been made to a much lesser extent than translocations; nevertheless, a handful of studies have reported ranges of unbalanced sperm of $1 \%-$ $54 \% .^{55-59}$

\section{INTERCHROMOSOMAL EFFECT (ICE)}

Interestingly, the presence of a structural chromosomal aberration has in many cases exhibited an increased frequency of chromosomal abnormalities that involve chromosomes other than those involved in the rearrangement (reviewed by Ref. 60). This ICE refers to the abnormal behavior of one or more chromosomes not involved in the rearrangement. Thus, individuals with a balanced translocation may be at an increased risk of non-disjunction events for other chromosomes as well as being at risk for aneuploidy for the segments involved in the structural rearrangement. Studies that have investigated aneuploidy levels in the sperm of carriers of structural chromosomal aberrations, have identified an ICE in $58 \%$ of Robertsonian translocation carriers and $64 \%$ of reciprocal translocation carriers. ${ }^{60}$ In addition, to the increased rate of aneuploidy observed in the sperm, PGD studies have also confirmed a higher rate of chromosomal aneuploidy in embryos for chromosomes not involved in the rearrangement. ${ }^{60}$

\section{NUMERICAL SEX CHROMOSOMAL ABNORMALITIES AND INFERTILITY}

Numerical sex chromosomal abnormalities in males are relatively common with Klinefelter syndrome (47,XXY) and 47,XYY syndrome each occurring in approximately 1-2 in 1000 live births. ${ }^{61} \mathrm{~A}$ high proportion of Klinefelter syndrome males are only identified when they undergo fertility assessments. The non-mosaic form of Klinefelter syndrome accounts for around $11 \%$ of azoospermic individuals, whereas mosaic individuals often present with oligozoospermia. ${ }^{62}$ Failure to identify Klinefelter syndrome is in part, due to the low awareness of the condition and the misapprehension that all individuals present with the classical phenotype (tall, gynecomastia and hypogonadism). However, it is now clear that Klinefelter syndrome has a highly variable phenotype. ${ }^{44}$ Individuals with $47, \mathrm{XYY}$ are often fertile but appear to have an increased likelihood of infertility compared to karyotypically normal 46,XY males. ${ }^{63}$ Given the presence of an additional sex chromosome in both Klinefelter and 47,XYY syndrome males, there is a theoretical risk of sex chromosomal aneuploidy in at least $50 \%$ of their sperm. A handful of studies have subsequently addressed whether this is the case by analyzing the aneuploidy frequencies in the sperm of mosaic and non-mosaic Klinefelter syndrome. For the most part, these studies all report significant increases in sex chromosomal aneuploidy in the sperm of these individuals compared to controls, with higher frequencies reported for non-mosaic individuals with an average of $6 \%$ aneuploidy (range: $1 \%-25 \%$ ) versus an average of $3 \%$ (range: $0-7 \%$ ) aneuploidy in mosaic 46,XY/47,XXY individuals (reviewed by Refs. 33, 47 and 48). In the case of $47, X Y Y$ individuals, aneuploidy levels have frequently been reported to be significantly higher than that of karyotypically normal men, but are often lower than those reported for Klinefelter syndrome with an average aneuploidy level of 4\% (range: $0.1 \%-14 \%$ ) (reviewed by Ref. 33). It is clear from these studies that some aneuploid cells are capable of initiating and completing meiosis resulting in aneuploid gametes. However, there does appear to be some as of yet unknown meiotic checkpoint that is efficiently eliminating a large proportion of aneuploid sperm. Despite this, couples should be counseled appropriately regarding the increased risk of aneuploid offspring. To date, the results are somewhat reassuring in that only approximately $10 \%$ of published cases have resulted in aneuploid offspring (two 47,XXY conceptuses). ${ }^{64,65}$ When PGD has been carried out in embryos from these individuals, the level of aneuploidy reported in sperm has been mirrored by an equivalent increase in aneuploidies in the resulting embryos. ${ }^{66,67}$ Obviously, the number of published studies is still relatively small for conclusions to be made and applied for genetic counseling purposes, but as with chromosomal translocations, there is still sufficient evidence to suggest that chromosomal abnormalities, either numerical or structural in nature, have the ability to initiate and complete meiosis and fertilize oocytes resulting in aneuploid conceptuses.

\section{Y CHROMOSOMAL MICRODELETIONS AND INFERTILITY}

One of the most commonly identified molecular genetic causes of male infertility has been sub-microscopic deletions (not visible by conventional cytogenetic analysis) on the Y chromosome. At present, three different spermatogenetic loci azoospermia factors (AZFa, AZFb and $A Z F c$ ) have been mapped to the long arm of the Y chromosome. Deletions within the AZF region can result in varying degrees of spermatogenic failure and hence, infertility, ${ }^{68}$ the prevalence of which increases with the severity of infertility. Microdeletions within the AZF region occur in approximately $4 \%$ of males with oligozoospermia; $14 \%$ of males with severe oligozoospermia; and $18 \%$ in nonobstructive azoospermia males. ${ }^{69}$ The vast majority of microdeletions arise de novo and have been attributed to intrachromosomal homologous recombination within unstable amplicons clustered within this region. ${ }^{70}$ Microdeletions remove one or more of these genes, and as a result cause varying defects in spermatogenesis. Candidate genes within the AZF regions have been studied extensively and are believed to play critical roles in germ cell cycle regulation and meiosis. Nevertheless, this has not yet led to the identification of the molecular basis for defective spermatogenesis. ${ }^{71}$ Despite this, clear genotypephenotype correlations are emerging. ${ }^{72}$ The most common Yq microdeletions occur in the AZFc region, in part due to its relatively large size compared to the AZFa and b, and account for approximately $60 \%$ of reported microdeletions. ${ }^{44}$ Of these cases, about two-thirds of individuals are azoospermic, of which sperm is recoverable by testicular sperm extraction for use in ICSI in about $50 \%$ of cases. ${ }^{73,74}$ The remaining AZFc microdeletion cases often present with severe oligozoospermia. Deletions within the AZFa region are often the most severe with individuals frequently presenting with Sertoli cell-only syndrome. ${ }^{74,75}$ Various patterns of spermatogenesis arrest have been reported with $\mathrm{AZFb}$ microdeletions ranging from Sertoli cell-only syndrome to hypospermatogenesis. ${ }^{74,75}$ However, in AZFb cases, the most frequent observation is germ cell arrest at the primary spermatocyte stage. ${ }^{72}$ When microdeletions encompass more than one region, the genotype-phenotype correlations are unsurprisingly more complex with wide ranging spermatogenic phenotypes reported. However, 
patients with $\mathrm{AZFb}+\mathrm{c}$ deletions generally have a poor success rate of obtaining sperm for use in ICSI even through the use of testicular sperm extraction, which has obvious clinical ramifications. ${ }^{76}$ In addition, to the relatively large microdeletions mentioned previously, there are increasing numbers of reports of partial deletions within the AZF regions. The most commonly reported is the gr/gr deletion which results in the deletion of about half of the AZFc region. The phenotypic effect of the gr/gr mutation remains somewhat controversial with some studies reporting little or no effect on sperm concentration but an association with infertility, ${ }^{77}$ whereas others report an association between the gr/gr mutation and oligoor azoospermia. ${ }^{78,79}$ It should be noted that mutations in genes within the AZF region such as USP9Y have been linked to spermatogenic failure. However, reports demonstrate that these mutations tend to be associated with a highly variable phenotype and hence, at present, screening for these mutations should not be routinely implemented in a clinical setting. ${ }^{80}$ Also worthy of consideration is the unusual genomic landscape of the $\mathrm{Y}$ chromosome which includes a large number of copy number variants. ${ }^{81,82}$ It has recently come to light that these copy number variants may be associated with male infertility.

When sperm is available for ICSI in Yq microdeletion individuals, it is important to provide couples with appropriate genetic counseling as the Yq microdeletion will inevitably be passed on to all of their male offspring which will ultimately mean that all male offspring will have reduced infertility.

\section{SHORTCOMINGS OF PRE-ARRAY TECHNOLOGIES FOR PGD}

Aneuploidy screening of embryos was first performed using FISH analysis of cells biopsied from day-3 embryos, ${ }^{27,83-86}$ trophectoderm cells biopsied from blastocyst stage embryos ${ }^{87}$ or polar bodies biopsied from oocytes or zygotes. ${ }^{88-90}$ FISH-based testing was able to analyze between 5 and 12 chromosomes in each oocyte or embryo, but was unable to provide a full evaluation of all 24 chromosomes. It has become clear from the conflicting studies on aneuploidy screening using FISH-based testing that a better technology was needed to move the field into the future and finally attain the predicted benefit of aneuploidy screening.

\section{Array-based testing of aneuploidy}

Comparative genomic hybridization (CGH), a technique related to FISH, was first applied to day-3 embryo biopsies in $1999 .{ }^{91-95}$ This new technique allowed for analysis of 24 chromosomes from a single cell and was a great leap forward from FISH-based testing. However, conventional CGH is time-consuming and incompatible with day-3 biopsy and fresh embryo transfer in the same cycle. At the time of its use, embryo cryopreservation was a relatively inefficient technique and the low survival rate of frozen/thawed embryos likely eliminated any benefits chromosomal screening may have had. For these reasons, CGH was temporarily abandoned and FISH-based testing for aneuploidy continued for the next 8-10 years.

More recently, two new testing platforms have come into use, microarray CGH (array-CGH (aCGH) $)^{96-99}$ and single nucleotide polymorphism (SNP) microarrays. ${ }^{100-103}$ These testing platforms allow for comprehensive chromosomal analysis of single cells from day- 3 biopsy and yield results in $24 \mathrm{~h}$. The rapid turnaround time for these methods eliminates the need to cryopreserve embryos, while testing is carried out. The use of array-based platforms has dramatically decreased the use of FISH-based testing in most laboratories worldwide.
aCGH is already widely used for the cytogenetic analysis of prenatal and postnatal samples ${ }^{104-107}$ as it is rapid, cost-effective and allows chromosomal regions to be screened at high resolution. Several types of aCGH platform are available for the purposes of aneuploidy screening. The variety most commonly used for the purpose of PGD utilizes bacterial artificial chromosomal probes, about 150000 bp in length, covering all chromosomal bands and giving a $4 \mathrm{MB}$ or lower resolution. A microarray recently validated for PGD had 4000 probes and thus covered $\sim 25 \%$ of the genome sequence. ${ }^{103}$

SNPs are areas of the genome where a single nucleotide in the DNA sequence varies within the population. Most SNPs are biallelic, existing in one of two forms, and are found scattered throughout the genome. By determining the genotype of multiple SNPs along the length of each chromosome, a haplotype (a contiguous series of polymorphisms on the same chromosome) can be assembled. This ultimately allows the inheritance of individual chromosomes or pieces of chromosomes to be tracked from parents to embryos. Current SNP microarrays simultaneously assay hundreds of thousands of SNPs, while utilizing powerful software to distinguish how many copies of each chromosome was inherited by an embryo. ${ }^{100,101,108}$

These new array-based testing platforms are highly informative at multiple loci, readily automated, less subjective and theoretically less prone to errors. All of the new generation of chromosomal screening methods (CGH, aCGH and SNP microarrays) rely on whole genome amplification to amplify DNA from the single cell or small number of cells removed from a developing embryo. ${ }^{109}$

Currently, a few PGD groups around the world are validating SNP microarrays and analysis software for clinical use in PGD for aneuploidy screening. It is expected that data from the clinical use of SNP microarrays will closely match the data from CGH and aCGH testing. While the technologies differ greatly, both types of arrays (CGH-based and SNP-based) are trying to answer the same question; how many copies of each chromosome are present in a sample?

\section{CONCLUSIONS}

The advent of ICSI in $1992^{110}$ revolutionized the treatment of male infertility and was rapidly adopted in IVF clinics worldwide, ${ }^{111}$ as up until this point there was little hope for infertile men to have biological children. However, since its inception, concerns have been raised about the safety of ICSI, especially in regard to the genetic consequences of utilizing sperm from infertile men. This is of particular importance, given the risk of transmission of reduced fertility ( $Y$ chromosomal microdeletions, chromosomal rearrangements) and the risk of aneuploid offspring due to higher levels of sperm aneuploidy or unbalanced sperm in chromosomal rearrangements. Given the aforementioned risk of chromosomal abnormalities, it would be wise to perform routine karyotyping prior to IVF/ICSI in infertile men with unexplained spermatogenic failure and a reduced sperm count (less than 10 million sperm per $\mathrm{ml}$ ); and Y chromosomal microdeletion analysis in men with severe oligozoospermia (less than 5 million sperm per $\mathrm{ml}$ ) or azoospermia. ${ }^{112,113}$ In a survey of the United Kingdom IVF centers, clinicians and genetic counselors were questioned as to whether they routinely perform sperm aneuploidy screening and if they perceive there to be a genetic risk to offspring conceived by ICSI. The vast majority indicated that while their center rarely performed such screening, there was merit in doing so. ${ }^{30}$ However, it is clear that we need to be able to provide more direct evidence of the risk and identify patients who would benefit from screening to allow patients to be appropriately counseled regarding the potential genetic repercussions of ICSI. 
We are still a long way away from being able to answer these questions, but published studies somewhat counter-intuitively suggest that there is little or no evidence that aneuploid sperm are at any disadvantage in fertilizing an oocyte compared to sperm with a normal haploid complement. In fact, quite the opposite may be true as some studies have convincingly demonstrated a distinct lack of selection against chromosomally abnormal sperm. Albeit relatively small numbers of studies, there is evidence to suggest that increased sperm aneuploidy translates to increased aneuploidy in embryos. In addition, the approximate threefold increase in sperm aneuploidy we observe in infertile populations is apparently mirrored by a threefold increase in de novo chromosomal abnormalities in children born after ICSI. ${ }^{114-117}$ In the case of chromosomal translocations, sperm FISH and PGD data clearly demonstrate that a very high percentage of sperm are unbalanced and this in turn translates to a high proportion of unbalanced embryos as determined by PGD. Despite this, what is not yet clear is why some individuals are predisposed to a generalized tendency for chromosomal non-disjunction or why individuals with the same phenotype, e.g., 47,XYY syndrome, have marked variation in sperm aneuploidy frequencies. The idea of a meiotic checkpoint has been postulated that may function to eliminate some or the vast majority of aneuploid gametes. If this is the case, alterations in the functioning of this checkpoint in some individuals might account for the variability in aneuploidy observed between studies. Variability in some cases is very likely due to meiotic abnormalities, and there are certainly emerging data suggesting that aneuploidy is closely associated with errors in chromosomal synapsis during meiosis and a reduction in meiotic recombination. ${ }^{118,119}$ In the case of individuals with numerical or structural chromosomal aberrations, the size of the region and chromosomes involved will undoubtedly influence chromosomal non-disjunction.

Virtually all published studies report a huge variation in sperm aneuploidy frequencies, whether they investigate sperm aneuploidy levels in infertile men or in individuals who are carriers of structural chromosomal aberrations. The tremendous amount of variation between individuals makes understandable and predictive paternal aneuploidy risk assessments for offspring conceived by IVF/ICSI virtually impossible in a clinical situation. If we take reciprocal translocations for example, levels of unbalanced sperm reported range from $29 \%$ to $81 \%$. Clearly, patients cannot and will not be able to make informed decisions if given such a range. However, if individualized sperm assessments were undertaken, an individual with 29\% vs. $81 \%$ aneuploid sperm would be given very different risk assessments. What is apparent from the current data is that an individualized assessment of the aneuploidy frequencies in sperm may be a more appropriate genetic counseling tool than applying a blanket risk assessment to all individuals with the same type of infertility or karyotype abnormality. If performed routinely in a clinical setting, individualized assessments of sperm aneuploidy will undoubtedly further our understanding of paternal etiology of aneuploidy, but also be of benefit to the patient allowing individualized estimates of risk for genetic counseling. However, a number of drawbacks have hindered routine implementation of sperm aneuploidy clinically (reviewed by Refs. 31-33), but briefly include: (i) the number of sperm required to be scored is significant (minimum of 5000) and is thus costly due to its labor intensiveness; (ii) only a handful of chromosomes (3-5) can be scored per sperm; (iii) we are unable to test individual sperm to be used in IVF or ICSI procedures; (iv) a direct association between sperm and embryo aneuploidy is still not proven from the small studies to date, thus making clinical recommendations difficult until larger, more comprehensive studies are performed.
Despite this, what is clear is that array-based testing platforms will potentially revolutionize our understanding of the molecular genetic basis of infertility. SNP-based testing approaches offer a great deal of information and insight into the genetic makeup of the sample tested. SNP-based microarrays applied to PGD for chromosomal rearrangements can differentiate between normal and balanced (carrier) embryos. This may allow patients that carry chromosomal rearrangements the ability to choose to transfer chromosomally normal embryos preferentially over embryos that are balanced carriers of the parental translocation. This preferential transfer would allow patients to eliminate potential infertility in future generations. However, as discussed previously, there are precious few normal/ balanced embryos diagnosed in each cycle $(<25 \%)$; therefore, most patients will not have the luxury of choosing between the two. Another advantage of SNP-based technology is that it should also offer a single platform for a large number of single gene defects to be tested through PGD without the need for patient-specific test workups. ${ }^{100}$ Such patient-specific workups can be extraordinarily time-consuming and difficult to perform and thus delay IVF/ICSI cycles and significantly increase the cost. In addition, qualitative analysis of SNP-based testing data may ultimately allow for analysis of parental haplotypes and, therefore, the detection of the parental origin of any chromosomal abnormalities. ${ }^{120}$ This will be valuable in determining the true incidence of aneuploidy in sperm and its impact on aneuploidy in embryos.

\section{COMPETING FINANCIAL INTERESTS}

The author declares no competing financial interests.

1 O'Flynn O'Brien KL, Varghese AC, Agarwal A. The genetic causes of male factor infertility: a review. Fertil Steril 2010; 93: 1-12.

2 de Kretser DM. Male infertility. Lancet 1997; 349: 787-90.

3 Tempest HG, Martin RH. Cytogenetic risks in chromosomally normal infertile men. Curr Opin Obstet Gynecol 2009; 21: 223-7.

4 Berger R. The incidence of constitutional chromosome aberrations. J Genet Hum 1975; 23: 42-9.

5 Shi $Q$, Martin RH. Aneuploidy in human sperm: a review of the frequency and distribution of aneuploidy, effects of donor age and lifestyle factors. Cytogenet Cell Genet 2000; 90: 219-26.

6 Hassold T, Hunt P. To err (meiotically) is human: the genesis of human aneuploidy. Nat Rev Genet 2001; 2: 280-91.

7 Hassold T, Hunt PA, Sherman S. Trisomy in humans: incidence, origin and etiology. Curr Opin Genet Dev 1993; 3: 398-403.

8 Lyon MF. Possible mechanisms of X chromosome inactivation. Nat New Biol 1971; 232: 229-32.

9 Hassold T, Hunt P. Maternal age and chromosomally abnormal pregnancies: what we know and what we wish we knew. Curr Opin Pediatr 2009; 21 : 703-8.

10 Yanowitz J. Meiosis: making a break for it. Curr Opin Cell Biol 2010; 22: 744-51.

11 Fragouli E, Alfarawati S, Goodall NN, Sanchez-Garcia JF, Colls P et al. The cytogenetics of polar bodies: insights into female meiosis and the diagnosis of aneuploidy. Mol Hum Reprod 2011; 17: 286-95.

12 Gabriel AS, Thornhill AR, Ottolini CS, Gordon A, Brown AP et al. Array comparative genomic hybridisation on first polar bodies suggests that non-disjunction is not the predominant mechanism leading to aneuploidy in humans. J Med Genet 2011; 48: 433-7.

13 Kuliev A, Zlatopolsky Z, Kirillova I, Spivakova J, Cieslak Janzen J. Meiosis errors in over 20,000 oocytes studied in the practice of preimplantation aneuploidy testing. Reprod Biomed Online 2011; 22: 2-8.

14 Handyside AH. Preimplantation genetic diagnosis after 20 years. Reprod Biomed Online 2010; 21: 280-2.

15 Simpson JL. Preimplantation genetic diagnosis at 20 years. Prenat Diagn 2010; 30 682-95.

16 Bielanska M, Tan SL, Ao A. Chromosomal mosaicism throughout human preimplantation development in vitro: incidence, type, and relevance to embryo outcome. Hum Reprod 2002; 17: 413-9.

17 Magli MC, Gianaroli L, Ferraretti AP, Lappi M, Ruberti A et al. Embryo morphology and development are dependent on the chromosomal complement. Fertil Steril 2007; 87 534-41. 
18 Munne S, Alikani M, Tomkin G, Grifo J, Cohen J. Embryo morphology, developmental rates, and maternal age are correlated with chromosome abnormalities. Fertil Steril 1995; 64: 382-91.

19 Munne S, Chen S, Colls P, Garrisi J, Zheng X et al. Maternal age, morphology, development and chromosome abnormalities in over 6000 cleavage-stage embryos. Reprod Biomed Online 2007; 14: 628-34.

20 Schoolcraft WB, Fragouli E, Stevens J, Munne S, Katz-Jaffe MG et al. Clinical application of comprehensive chromosomal screening at the blastocyst stage. Fertil Steril 2010; 94: 1700-6.

21 Carp H, Toder V, Aviram A, Daniely M, Mashiach S et al. Karyotype of the abortus in recurrent miscarriage. Fertil Steril 2001; 75: 678-82.

22 Daniely M, Aviram-Goldring A, Barkai G, Goldman B. Detection of chromosomal aberration in fetuses arising from recurrent spontaneous abortion by comparative genomic hybridization. Hum Reprod 1998; 13: 805-9.

23 Fritz B, Hallermann C, Olert J, Fuchs B, Bruns M et al. Cytogenetic analyses of culture failures by comparative genomic hybridisation (CGH) - re-evaluation of chromosome aberration rates in early spontaneous abortions. Eur J Hum Genet 2001; 9: 539-47.

24 Hassold T, Chen N, Funkhouser J, Jooss T, Manuel B et al. A cytogenetic study of 1000 spontaneous abortions. Ann Hum Genet 1980; 44: 151-78.

25 Menasha J, Levy B, Hirschhorn K, Kardon NB. Incidence and spectrum of chromosome abnormalities in spontaneous abortions: new insights from a 12-year study. Genet Med 2005; 7: 251-63.

26 Qumsiyeh MB, Kim KR, Ahmed MN, Bradford W. Cytogenetics and mechanisms of spontaneous abortions: increased apoptosis and decreased cell proliferation in chromosomally abnormal villi. Cytogenet Cell Genet 2000; 88: 230-5.

27 Munne S, Lee A, Rosenwaks Z, Grifo J, Cohen J. Diagnosis of major chromosome aneuploidies in human preimplantation embryos. Hum Reprod 1993; 8: 2185-91.

28 Shi Q, Martin RH. Aneuploidy in human spermatozoa: FISH analysis in men with constitutional chromosomal abnormalities, and in infertile men. Reproduction $2001 ; 121$ : 655-66.

29 Tempest HG, Griffin DK. The relationship between male infertility and increased levels of sperm disomy. Cytogenet Genome Res 2004; 107: 83-94.

30 Griffin DK, Hyland P, Tempest HG, Homa ST. Safety issues in assisted reproduction technology: should men undergoing ICSI be screened for chromosome abnormalities in their sperm? Hum Reprod 2003; 18: 229-35.

31 Carrell DT. The clinical implementation of sperm chromosome aneuploidy testing: pitfalls and promises. J Androl 2008; 29: 124-33.

32 Hann MC, Lau PE, Tempest HG. Meiotic recombination and male infertility: from basic science to clinical reality? Asian J Androl 2011; 13: 212-8.

33 Tempest HG. Meiotic recombination errors the origin of sperm aneuploidy and clinical recommendations. Syst Biol Reprod Med 2011; 57: 93-101.

34 Blanco J, Gabau E, Gomez D, Baena N, Guitart M et al. Chromosome 21 disomy in the spermatozoa of the fathers of children with trisomy 21 , in a population with a high prevalence of Down syndrome: increased incidence in cases of paternal origin. Am J Hum Genet 1998; 63: 1067-72.

35 Eskenazi B, Wyrobek AJ, Kidd SA, Lowe X, Moore D 2nd et al. Sperm aneuploidy in fathers of children with paternally and maternally inherited Klinefelter syndrome. Hum Reprod 2002; 17: 576-83

36 Martinez-Pasarell O, Nogues C, Bosch M, Egozcue J, Templado C. Analysis of sex chromosome aneuploidy in sperm from fathers of Turner syndrome patients. Hum Genet 1999; 104: 345-9.

37 Martinez-Pasarell O, Templado C, Vicens-Calvet E, Egozcue J, Nogues C. Paternal sex chromosome aneuploidy as a possible origin of Turner syndrome in monozygotic twins: case report. Hum Reprod 1999; 14: 2735-8.

38 Tang SS, Gao H, Robinson WP, Ho Yuen B, Ma S. An association between sex chromosomal aneuploidy in sperm and an abortus with $45, \mathrm{X}$ of paternal origin: possible transmission of chromosomal abnormalities through ICSI. Hum Reprod 2004; 19: 147-51.

39 Moosani N, Chernos J, Lowry RB, Martin RH, Rademaker A. A 47, XXY fetus resulting from ICSI in a man with an elevated frequency of $24, X Y$ spermatozoa. Hum Reprod 1999; 14: 1137-8.

40 Nicopoullos JD, Gilling-Smith C, Almeida PA, Homa S, Nice L et al. The role of sperm aneuploidy as a predictor of the success of intracytoplasmic sperm injection? Hum Reprod 2008; 23: 240-50.

41 Petit FM, Frydman N, Benkhalifa M, Le Du A, Aboura A et al. Could sperm aneuploidy rate determination be used as a predictive test before intracytoplasmic sperm injection? J Androl 2005; 26: 235-41.

42 Gianaroli L, Magli MC, Ferraretti AP. Sperm and blastomere aneuploidy detection in reproductive genetics and medicine. J Histochem Cytochem 2005; 53: 261-7.

43 Nagvenkar P, Zaveri K, Hinduja I. Comparison of the sperm aneuploidy rate in severe oligozoospermic and oligozoospermic men and its relation to intracytoplasmic sperm injection outcome. Fertil Steril 2005; 84: 925-31.

44 McLachlan RI, O'Bryan MK. Clinical review: state of the art for genetic testing of infertile men. J Clin Endocrinol Metab 2010; 95: 1013-24.

45 Tempest HG, Simpson JL. Role of preimplantation genetic diagnosis (PGD) in current infertility practice. Int J Infertil Fetal Med 2010; 1: 1-10.

46 Shah K, Sivapalan G, Gibbons N, Tempest H, Griffin DK. The genetic basis of infertility. Reproduction 2003; 126: 13-25.

47 Ferlin A, Garolla A, Foresta C. Chromosome abnormalities in sperm of individuals with constitutional sex chromosomal abnormalities. Cytogenet Genome Res 2005; 111: 310-6.
48 Sarrate Z, Blanco J, Anton E, Egozcue S, Egozcue J et al. FISH studies of chromosome abnormalities in germ cells and its relevance in reproductive counseling. Asian $J$ Androl 2005; 7: 227-36

49 Harper JC, Coonen E, de Rycke M, Harton G, Moutou C et al. ESHRE PGD Consortium data collection X: cycles from January to December 2007 with pregnancy follow-up to October 2008. Hum Reprod 2010; 25: 2685-707.

50 Kuliev A, Janzen JC, Zlatopolsky Z, Kirillova I, Ilkevitch Y et al. Conversion and nonconversion approach to preimplantation diagnosis for chromosomal rearrangements in 475 cycles. Reprod Biomed Online 2010; 21: 93-9.

51 Munne S. Analysis of chromosome segregation during preimplantation genetic diagnosis in both male and female translocation heterozygotes. Cytogenet Genome Res 2005; 111: 305-9.

52 Fischer J, Colls P, Escudero T, Munne S. Preimplantation genetic diagnosis (PGD) improves pregnancy outcome for translocation carriers with a history of recurrent losses. Fertil Steril 2010; 94: 283-9.

53 Brown GM, Leversha M, Hulten M, Ferguson-Smith MA, Affara NA et al. Genetic analysis of meiotic recombination in humans by use of sperm typing: reduced recombination within a heterozygous paracentric inversion of chromosome 9q32q34.3. Am J Hum Genet 1998; 62: 1484-92.

54 Chandley AC, McBeath S, Speed RM, Yorston L, Hargreave TB. Pericentric inversion in human chromosome 1 and the risk for male sterility. J Med Genet 1987; 24: 325-34.

55 Anton E, Blanco J, Egozcue J, Vidal F. Risk assessment and segregation analysis in a pericentric inversion inv6p23q25 carrier using FISH on decondensed sperm nuclei. Cytogenet Genome Res 2002; 97: 149-54.

56 Jaarola M, Martin RH, Ashley T. Direct evidence for suppression of recombination within two pericentric inversions in humans: a new sperm-FISH technique. Am J Hum Genet 1998; 63: 218-24.

57 Mikhaail-Philips MM, Ko E, Chernos J, Greene C, Rademaker A et al. Analysis of chromosome segregation in sperm from a chromosome 2 inversion heterozygote and assessment of an interchromosomal effect. Am J Med Genet A 2004; 127A: 139-43.

58 Mikhaail-Philips MM, McGillivray BC, Hamilton SJ, Ko E, Chernos J et al. Unusual segregation products in sperm from a pericentric inversion 17 heterozygote. Hum Genet 2005; 117: 357-65.

59 Yakut T, Acar H, Egeli U, Kimya Y. Frequency of recombinant and nonrecombinant products of pericentric inversion of chromosome 1 in sperm nuclei of carrier: by FISH technique. Mol Reprod Dev 2003; 66: 67-71.

60 Martin RH. Cytogenetic determinants of male fertility. Hum Reprod Update 2008; 14 : 379-90.

61 Morris JK, Alberman E, Scott C, Jacobs P. Is the prevalence of Klinefelter syndrome increasing? Eur J Hum Genet 2008; 16: 163-70.

62 van Assche E, Bonduelle M, Tournaye H, Joris H, Verheyen G et al. Cytogenetics of infertile men. Hum Reprod 1996 Dec; 11 Suppl 4: 1-24; discussion 25-6.

63 Yoshida A, Miura K, Shirai M. Cytogenetic survey of 1,007 infertile males. Urol Int 1997; 58: 166-76

64 Friedler S, Raziel A, Strassburger D, Schachter M, Bern O et al. Outcome of ICSI using fresh and cryopreserved-thawed testicular spermatozoa in patients with non-mosaic Klinefelter's syndrome. Hum Reprod2001; 16: 2616-20.

65 Ron-El R, Strassburger D, Gelman-Kohan S, Friedler S, Raziel A et al. A 47, XXY fetus conceived after ICSI of spermatozoa from a patient with non-mosaic Klinefelter's syndrome: case report. Hum Reprod 2000; 15: 1804-6.

66 Gonzalez-Merino E, Hans C, Abramowicz M, Englert Y, Emiliani S. Aneuploidy study in sperm and preimplantation embryos from nonmosaic 47,XYY men. Fertil Steril 2007; 88: 600-6.

67 Staessen C, Tournaye H, van Assche E, Michiels A, van Landuyt L et al. PGD in 47,XXY Klinefelter's syndrome patients. Hum Reprod Update 2003; 9: 319-30.

68 Simoni M. Molecular diagnosis of $Y$ chromosome microdeletions in Europe: state-ofthe-art and quality control. Hum Reprod 2001; 16: 402-9.

69 Simoni M, Bakker E, Krausz C. EAA/EMQN best practice guidelines for molecular diagnosis of $y$-chromosomal microdeletions. State of the art 2004. Int J Androl 2004; $27: 240-9$

70 Navarro-Costa P, Goncalves J, Plancha CE. The AZFc region of the $Y$ chromosome: at the crossroads between genetic diversity and male infertility. Hum Reprod Update 2010; 16: 525-42

71 Tyler-Smith C, Krausz C. The will-o'-the-wisp of genetics-hunting for the azoospermia factor gene. N Engl J Med 2009; 360: 925-7.

72 Vogt PH, Edelmann A, Kirsch S, Henegariu O, Hirschmann P et al. Human $Y$ chromosome azoospermia factors (AZF) mapped to different subregions in Yq11. Hum Mol Genet 1996; 5: 933-43.

73 Hopps CV, Mielnik A, Goldstein M, Palermo GD, Rosenwaks Z et al. Detection of sperm in men with $\mathrm{Y}$ chromosome microdeletions of the AZFa, AZFb and AZFc regions. Hum Reprod 2003; 18: 1660-5.

74 Krausz C, Quintana-Murci L, McElreavey K. Prognostic value of $Y$ deletion analysis: what is the clinical prognostic value of $Y$ chromosome microdeletion analysis? Hum Reprod 2000; 15: 1431-4.

75 Brandell RA, Meilnik A, Liotta D, Ye Y, Veeck LL et al. AZFb deletions predict the absence of spermatozoa with testicular sperm extraction: preliminary report of a prognostic genetic test. Hum Reprod 1998; 13: 2812-15.

76 Stahl PJ, Masson P, Mielnik A, Marean MB, Schlegel PN et al. A decade of experience emphasizes that testing for $Y$ microdeletions is essential in American men with azoospermia and severe oligozoospermia. Fertil Steril 2010; 94: 1753-6.

77 Lynch M, Cram DS, Reilly A, O'Bryan MK, Baker HW et al. The Y chromosome gr/gr subdeletion is associated with male infertility. Mol Hum Reprod 2005; 11: 507-12. 
78 Giachini C, Laface I, Guarducci E, Balercia G, Forti G et al. Partial AZFc deletions and duplications: clinical correlates in the Italian population. Hum Genet 2008; 124: 399-410

79 Visser L, Westerveld GH, Korver CM, van Daalen SK, Hovingh SE et al. Y chromosome gr/gr deletions are a risk factor for low semen quality. Hum Reprod 2009; 24: 2667 73.

80 Tyler-Smith C, Krausz C. The Will-o'-the-Wisp of genetics-hunting for the azoospermia factor gene. N Engl J Med 2009; 369: 925-27.

81 Krausz C, Chianese C, Giachini C, Guarducci E, Laface I et al. The Y chromosomelinked copy number variations and male fertility. J Endocrinol Invest 2011; 35: 376 82.

82 Jobling MA. Copy number variation on the human $\mathrm{Y}$ chromosome. Cytogenet Genome Res 2008; 123: 253-62

83 Colls P, Escudero T, Cekleniak N, Sadowy S, Cohen J et al. Increased efficiency of preimplantation genetic diagnosis for infertility using 'no result rescue'. Fertil Steril 2007; 88: 53-61.

84 Colls P, Goodall N, Zheng X, Munne S. Increased efficiency of preimplantation genetic diagnosis for aneuploidy by testing 12 chromosomes. Reprod Biomed Online 2009, 19: 532-8.

85 Magli MC, Sandalinas M, Escudero T, Morrison L, Ferraretti AP et al. Double locus analysis of chromosome 21 for preimplantation genetic diagnosis of aneuploidy. Prenat Diagn 2001; 21: 1080-5.

86 Munne S, Magli C, Bahce M, Fung J, Legator M et al. Preimplantation diagnosis of the aneuploidies most commonly found in spontaneous abortions and live births: $\mathrm{XY}, 13$, 14, 15, 16, 18, 21, 22. Prenat Diagn 1998; 18: 1459-66.

87 Jansen RP, Bowman MC, de Boer KA, Leigh DA, Lieberman DB et al. What next for preimplantation genetic screening (PGS)? Experience with blastocyst biopsy and testing for aneuploidy. Hum Reprod 2008; 23: 1476-8.

88 Kuliev A, Cieslak J, Ilkevitch Y, Verlinsky Y. Chromosomal abnormalities in a series of 6,733 human oocytes in preimplantation diagnosis for age-related aneuploidies. Reprod Biomed Online 2003; 6: 54-9.

89 Verlinsky Y, Kuliev A. Preimplantation diagnosis of common aneuploidies in infertile couples of advanced maternal age. Hum Reprod 1996; 11: 2076-7.

90 Verlinsky Y, Tur-Kaspa I, Cieslak J, Bernal A, Morris R et al. Preimplantation testing fo chromosomal disorders improves reproductive outcome of poor-prognosis patients. Reprod Biomed Online 2005; 11: 219-25.

91 Voullaire L, Wilton L, Slater H, Williamson R. Detection of aneuploidy in single cells using comparative genomic hybridization. Prenat Diagn 1999; 19: 846-51.

92 Wells D, Delhanty JD. Comprehensive chromosomal analysis of human preimplantation embryos using whole genome amplification and single cell comparative genomic hybridization. Mol Hum Reprod 2000; 6: 1055-62.

93 Wells D, Escudero T, Levy B, Hirschhorn K, Delhanty JD et al. First clinical application of comparative genomic hybridization and polar body testing for preimplantation genetic diagnosis of aneuploidy. Fertil Steril 2002; 78: 543-9.

94 Wells D, Sherlock JK, Handyside AH, Delhanty JD. Detailed chromosomal and molecular genetic analysis of single cells by whole genome amplification and comparative genomic hybridisation. Nucleic Acids Res 1999; 27: 1214-8.

95 Wilton L, Williamson R, McBain J, Edgar D, Voullaire L. Birth of a healthy infant after preimplantation confirmation of euploidy by comparative genomic hybridization. N Engl J Med 2001; 345: 1537-41.

96 Fishel S, Gordon A, Lynch C, Dowell K, Ndukwe G et al. Live birth after polar body array comparative genomic hybridization prediction of embryo ploidy - the future of IVF? Fertil Steril 2010; 93: 1006 e7-10.

97 Hellani A, Abu-Amero K, Azouri J, El-Akoum S. Successful pregnancies after application of array-comparative genomic hybridization in PGS-aneuploidy screening. Reprod Biomed Online 2008; 17: 841-7.

98 Hu DG, Webb G, Hussey N. Aneuploidy detection in single cells using DNA array-based comparative genomic hybridization. Mol Hum Reprod 2004; 10: 283-9.
99 Le Caignec C, Spits C, Sermon K, de Rycke M, Thienpont B et al. Single-cell chromosomal imbalances detection by array CGH. Nucleic Acids Res 2006; 34: e68.

100 Handyside AH, Harton GL, Mariani B, Thornhill AR, Affara N et al. Karyomapping: a universal method for genome wide analysis of genetic disease based on mapping crossovers between parental haplotypes. J Med Genet 2010; 47: 651-8.

101 Johnson DS, Gemelos G, Baner J, Ryan A, Cinnioglu C et al. Preclinical validation of a microarray method for full molecular karyotyping of blastomeres in a 24-h protocol. Hum Reprod 2010; 25: 1066-75.

102 Treff NR, Su J, Tao X, Miller KA, Levy B et al. A novel single-cell DNA fingerprinting method successfully distinguishes sibling human embryos. Fertil Steril 2010; 94: 477-84.

103 Munne S, Gutierrez-Mateo C, Sanchez-Garcia JF, Ketterson K, Prates R et al. Validation of microarray CGH for PGD by FISH reanalysis. Fertil Steril 2009; 92(Suppl S2): 0-6.

104 Beaudet AL, Belmont JW. Array-based DNA diagnostics: let the revolution begin. Annu Rev Med 2008; 59: 113-29.

105 Goobie S, Knijnenburg J, Fitzpatrick D, Sharkey FH, Lionel AC et al. Molecular and clinical characterization of de novo and familial cases with microduplication 3q29: guidelines for copy number variation case reporting. Cytogenet Genome Res 2008, 123: 65-78.

106 Sismani C, Kitsiou-Tzeli S, Ioannides M, Christodoulou C, Anastasiadou V et al. Cryptic genomic imbalances in patients with de novo or familial apparently balanced translocations and abnormal phenotype. Mol Cytogenet 2008; 1: 15.

107 Stejskalova E, Malis J, Snajdauf J, Pycha K, Urbankova H et al. Cytogenetic and array comparative genomic hybridization analysis of a series of hepatoblastomas. Cancer Genet Cytogenet 2009; 194: 82-7.

108 Treff NR, Su J, Kasabwala N, Tao X, Miller KA et al. Robust embryo identification using first polar body single nucleotide polymorphism microarray-based DNA fingerprinting. Fertil Steril 2010; 93: 2453-5.

109 Vanneste $\mathrm{E}$, Voet T, Le Caignec C, Ampe M, Konings $\mathrm{P}$ et al. Chromosome instability is common in human cleavage-stage embryos. Nat Med 2009; 15: 577-83.

110 Palermo G, Joris H, Devroey P, van Steirteghem AC. Pregnancies after intracytoplasmic injection of single spermatozoon into an oocyte. Lancet 1992. 340: 17-8.

111 Palermo GD, Neri QV, Hariprashad JJ, Davis OK, Veeck LL et al. ICSI and its outcome. Semin Reprod Med 2000; 18: 161-9.

112 McLachlan RI, O'Bryan MK, Clinical review\#: state of the art for genetic testing of infertile men. J Clin Endocrinol Metab 2010; 95: 1013-24.

113 Krausz C. Male infertility: pathogenesis and clinical diagnosis. Best Pract Res Clin Endocrinol Metab 2011; 25: 271-85.

114 Aboulghar H, Aboulghar M, Mansour R, Serour G, Amin Y et al. A prospective controlled study of karyotyping for 430 consecutive babies conceived through intracytoplasmic sperm injection. Fertil Steril 2001; 76: 249-53.

115 Bonduelle M, van Assche E, Joris H, Keymolen K, Devroey P et al. Prenatal testing in ICSI pregnancies: incidence of chromosomal anomalies in 1586 karyotypes and relation to sperm parameters. Hum Reprod 2002; 17: 2600-14.

116 Devroey $\mathrm{P}$, van Steirteghem A. A review of ten years experience of ICSI. Hum Reprod Update 2004; 10: 19-28.

117 van Steirteghem A, Bonduelle M, Devroey P, Liebaers I. Follow-up of children born after ICSI. Hum Reprod Update 2002; 8: 111-6.

118 Ferguson KA, Wong EC, Chow V, Nigro M, Ma S. Abnormal meiotic recombination in infertile men and its association with sperm aneuploidy. Hum Mol Genet 2007; 16 2870-9.

119 Sun F, Mikhaail-Philips M, Oliver-Bonet M, Ko E, Rademaker A et al. The relationship between meiotic recombination in human spermatocytes and aneuploidy in sperm. Hum Reprod 2008; 23: 1691-7.

120 Gabriel AS, Hassold TJ, Thornhill AR, Affara NA, Handyside AH et al. An algorithm for determining the origin of trisomy and the positions of chiasmata from SNP genotype data. Chromosome Res 2011; 19: 155-63. 